\title{
JURNAL PIONEER
}

VOLUME 10, Issue 1, June 2018: 27 - 39

\section{THE PSYCHOLOGICAL PROBLEMS IN SEXUAL DEVIATION OF CHRISTIANGREY IN FIFTY SHADES MOVIES}

\author{
Putri Rokhma Afifa \\ University of Abdurachman Saleh Situbondo \\ p.rochma@yahoo.com \\ Dian Maya Kurnia \\ University of Abdurachman Saleh Situbondo \\ aroundmaya86@gmail.com
}

\begin{abstract}
The research applied psychoanalysis and psychological approaches to analyze Christian's sexual deviation in Fifty Shades movies. This research used descriptive qualitative method to analyze the data. The research aimed at analyzing the causes of Christian's sexual deviation and the personality impact of his sexual deviation. The objects of this research were the first and second movies of Fifty Shades trilogy, they were Fifty Shades of Grey and Fifty Shades Darker. The data of this research were taken from Christian's dialogues, utterances, and actions related to the topic of this research. The findings of this research showed that Christian had sexual deviation related to sadistic things from his traumatic experience. Christian also had personality disorders as the impact of his sexual deviation. Christian had three personality disorders: histrionic, obsessivecompulsive, and narcissistic personalities.
\end{abstract}

Keywords: christian grey, psychological problems, sexual deviation, fifty shades movie 


\section{INTRODUCTION}

In general aims, the aim of movie is entertaining. Besides as an entertainment, movie is one of the literary works that in this modern era has developing, because it is very promising industry since many people love to spend their spare time to watching movie. Movie also becomes a tool for delivering an idea through audio-visual media. People in this industry use movie as the media to share their ideas and opinions about some phenomena in real life.

Fifty Shades movies are interesting movies that have a good storylines. Fifty Shades trilogy are chosen by the researcher because it is related to the topic that researcher chose to analyze. However, the researcher took the Fifty Shades of Grey and Fifty Shades Darker to analyze because the phenomena of sexual deviation is rarely encountered in our society. Besides, the researcher wanted to know more the causes why a person has a sexual deviation and also the impacts of sexual deviation through this movie.

Base on that, the researcher thought some of research problems and objectives of this research. The research problems are What are the causes of Christian Grey's sexual deviation in Fifty Shades movies? And what are Christian Grey's sexual deviation impacts to his personalities in Fifty Shades movies? Moreover, the objectives of this study are to find out the causes of Christian Grey's sexual deviation in Fifty Shades movies and to know the personality impacts of Christian Grey's sexual deviation in Fifty Shades movies.

\section{REVIEW OF LITERATURE}

\section{Psychoanalysis}

In psychoanalysis, Sigmund Freud (1961: 211-224) divides personality structure consist of three aspects, there are id, ego, and super ego. This theory believes that personality is formed through these aspects. Bressler (1994:165), "Freud bases his psychoanalysis on his model of human mind. This model represents the part of human mind psyche as three part: id, ego, and super ego". Id, ego, and super ego are the aspects in the personality that always. 


\section{Sexual Deviation}

Oltmanns \& Emery (2012:

318) explain sexual deviation as paraphilia, it is a condition in a person's sexual arousal and gratification depend on fantasizing about and engaging in sexual behavior that is abnormal and extreme.For some people, sexual deviation is strongly associated with unusual things and situations, such as inanimate objects, sexual contact with children, exhibiting their genitals to strangers, or inflicting pain on another person. According to Oltmanns \& Emery (2012: 318) the central features of all paraphilias are persistent sexual urges and fantasies that are associated with non-human objects, suffering or humiliation of partners, or children or non consenting persons.

\section{Causes of Sexual Deviation}

Mangal (2008: 220-221) explained that sexual deviation has causes which affect people who have it. There are six causes, such as: (1) Traumatic Experience

Generalized inhibitions and sexual ignorance (3) Deprivation of outlet for normal sex behavior (4) Fear and complexes associated with opposite sex and nor sex behavior (5) Conditioning to suitable abnormal pattern of sex behavior (6) Fixation of abnormal sex behavior.

\section{Personality Disorders}

Personality disorders are a type of mental health problem where the attitudes, beliefs and behaviors cause longstanding problems in life. An experience of personality disorder is unique to us. However, we may often experience difficulties in how we think about ourselves and others. Personality disorders based on Ruben (2015: 10) are considered separately from other forms of psychopathology. All of the personality disorders are based on exaggerated personality traits that are frequently disturbing or annoying to other people. Ruben (2015: 10) explains that ten personality disorders divide them into three groups or clusters: Cluster A, Cluster B, Cluster C.

Cluster A: Paranoid, Schizoid, and Schizotypal

Ruben (2015: 10) explains if personality disorders are divided into 
three clusters or groups. Clusters A consists of three personality disorders, there are paranoid, schizoid, and schizotypal. These personality have same behavior that socially odd, eccentric, and many more that shows poorly developed, and many psychiatric use a word "asocial" to mention a person who has these personality.

\section{Paranoid}

Paranoid personality disorder is characterized by the pervasive tendency to be inappropriately suspicious of other people's motives and behaviors. People who fit the description for this disorder are constantly on guard. They expect that other people are trying to harm them, and they take extraordinary precautions to avoid being exploited or injured. Ruben (2015: 12) mentions that paranoid personality has five characteristics, they are: (1) Guarded, defensive, distrustful, suspicious (2) Feels righteous, persecuted, blames other people, refuses new ideas (3) Feels exploited, harmed, deceived, betrayed, bears, grudges (4) Overanalyzes with no sufficient data (5) Unforgiving of any mistakes (7) Prone to passiveaggressive retaliation.

\section{Schizoid}

Schizoid is an uncommon personality in the general population. A person who has no desire for social or sexual relationships, is indifferent to others and to social norms and conventions, and lacks emotional response. Ruben (2015: 13) also mentions if schizoid is also traced to sensory, emotionally, or interpersonally deprived youngster raised either in parent hostile or parent -absent environments. Ruben (2015: 14) mentions that schizoid personality has five characteristics, they are: (1) Apathetic, indifferent, and isolate (2) Neither desire nor needs human contact, or sex (3) Uncaring about praise, criticism, flat, affect, detached (4) Long silences, zombie-like, poor social skills (5) Severe social anxiety and conflict avoidance. 


\section{Schizotypal}

\section{Schizotypal personality}

disorder centers around peculiar patterns of behavior rather than on the emotional restriction and social withdraw that are associated with schizoid personality disorder. In spite of their odd or unusual behaviors, people with schizotypal personality disorder are not psychotic or out of touch with reality. Their bizarre fantasies are not delusional, and their unusual perceptual experiences are not sufficiently real or compelling to be considered hallucinations. Ruben (2015: 16) mentions that schizotypal personality has five characteristics, they are: (1) Similar features to schizoid personality disorder (2)

Eccentric, bizarre, odd habits (3) Magical and odd belief, thinking, sound like word salad (4) Poor or no capacity for close relationships (5)

Inappropriate display of feelings.

\section{Cluster B: Antisocial, Borderline,} Narcissistic, and Histrionic

Cluster B consists of personality disorders of antisocial, borderline, histrionic, and narcissistic. Mostly, experts or psychiatrics use word "ballistic" to mention a person who has this disorder, and these characterized by dramatic, overly emotional, or unpredictable thinking or behavior.

\begin{abstract}
Antisocial
Antisocial personality disorder is defined in terms of a persistent pattern of irresponsible and antisocial behavior that begins during childhood or adolescence and continues into the adult years. According to Ruben (2015: 19) antisocial personality has six characteristics, they are: Impulsive, unruly, and adventureseeking (2) Deceitful, manipulative, liar, and charmer (3) Intimidator, instigator, aggressor, stalker, and predator (4) Conduct disorder in childhood (5) Mistreats partnersinfidelity, domestic violence (6) High risk of juvenile, adult crimes.
\end{abstract}

\section{Borderline}

Ruben (2015: 22) explains that borderline personality disorder is a diffuse category whose essential feature is a pervasive pattern of instability in mood and interpersonal relationships. People with this 
disorder finds it very difficult to be alone. People with borderline personality always feel worry if they are abandoned and also have great difficulty maintaining an integrated image of themselves that simultaneously incorporates their positive and negative features. According to Ruben (2015: 22) mentions that borderline personality has seven characteristics, they are (1) Unstable moods, (2) Idealize or demonize; admire or hate, (3) Clingy (demanding) or arrogantly independent, (4) Thrives on chaos; constant state of panic, and negative,

(5) Pervasive feeling of emptiness; terrified of abandonment, (6) Stormy, violent, and failed relationship, (7) Hypersensitive, wants constant feedback, and approval.

\section{Narcissistic}

Narcissistic personality disorder is a pervasive pattern of grandiosity, need for admiration, and inability to empathize with other people. Narcissistic people have a greatly exaggerated sense of their own importance. They are preoccupied with their own achievements and abilities. Narcissistic is also described as a personality which is arrogant, selfcentered, manipulative, and demanding. People with this personality usually are diagnosed in early adulthood and must be consistently evident in multiple context. Ruben (2015: 23) mentions that narcissistic personality has five characteristics, they are:

1. Has a grandiose sense of selfimportance.

2. Requires excessive admiration.

3. Regularly shows arrogant, haughty behaviors or attitudes.

4. Lacks empathy.

5. Believes that he or she is "special" and unique.

\section{Histrionic}

Histrionic personality disorder which is explained by Ruben (2015: 24) is a personality that is characterized by constant attentionseeking, emotional overreaction, and suggestibility. People with this disorder thrive on being the center of attention. They want the spotlight on them at all times. People with this disorder are uncomfortable or feel 
unappreciated when they are not the center of attention. As one of the disorder that is explained by Ruben (2015: 24), histrionic personality is characterized by these behaviors:

1. Self centeredness.

2. Constantly seeking reassurance or approval.

\section{Inappropriately}

seductive

appearance or behavior.

4.Overly concerned with physical appearance, and using physical appearance to draw attention.

5.Excessive dramatics with exaggerated displays of emotion.

\section{Cluster C: Avoidant, Dependent, and Obsessive-Compulsive} Cluster $\mathrm{C}$ is called the anxious, fearful cluster. It includes the avoidant, dependent, and obsessive-compulsive personality disorders. People with these disorders often appear to be nervous and fearful. Many clinicians are calling people who have this disorder as "coward" (Ruben, 2015: 30).

\section{Avoidant}

Avoidant personality disorder is characterized by a pervasive pattern of social discomfort, fear of negative evaluation, and timidity. People with this disorder tend to be socially isolated when outside their own family circle because they are afraid of criticism. Unlike people with schizoid personality disorder, they want to be liked by others, but they are extremely shy easily hurt by even minimal signs of disapproval from other people. Ruben explains (2015: 39) that avoidant personality has seven characteristics: (1) Easily hurt by criticism or disapproval, (2) No close friend, (3) Avoidance of activities or occupations that involve contact with others, (4) Showing excessive restraint in intimate relationships (5) Feeling socially inept, inferior, or unappealing to other people, (6) Feel shy in social situations or fear of doing something, (7) Exaggeration of potential difficulties.

\section{Dependent}

Dependent personality disorder according to Oltmanns \& Emery (2012: 228) is a pervasive pattern of submissive and clinging behavior. People with this disorder are afraid ofseparating from other 
people on whom they are dependent for advice and reassurance. Individuals with dependent personality disorder are often characterized by pessimism and selfdoubt, tend to belittle their abilities and assets, and may constantly refer to themselves as "stupid. "Characteristics of this personality explained by Ruben (2015: 41) are:

1.Difficulty making decisions without reassurance from others.

\section{Extreme passivity}

3.Problems expressing disagreements with others.

4. Avoiding personal responsibility.

5. Unable to meet ordinary demands of life.

6. Avoiding being alone.

\section{Obsessive-Compulsive}

Obsessive-Compulsive is characterized by a preoccupation with orderliness, perfectionism, mental and interpersonal control, at the expense of flexibility, openness, and efficiency (Oltmanns \& Emery, 2012: 228). Individuals with this disorder usually express affection in a highly controlled or stilted fashio $\mathrm{n}$ and may be very uncomfortable in the presence of others who are emotionally expressive.

Ruben (2015: 42) mentions there are five characteristics of obsessive-compulsive personality disorder, they are:

1. Excessive preoccupation with details, lists, orderliness, rules, procedures, or schedules.

2. Stiff, formal, or rigid mannerisms.

3. Perfectionism so stringent that it interferes with task completion.

4. Extreme frugality or miserliness.

5. Overwhelming need for order and environmental control.

\section{METHODOLOGY}

This research used Fifty Shades of Grey and Fifty Shades Darker movies as the data source, while the research data were got from Christian Grey's dialogues or utterances of this movie, and also from his behaviors. Research instrument of this study was the researcher as a subject of research. The researcher herself watched and analyzed the movies. Data analysis is the part of methodology to know how the data will be analyzed. There are two steps to analyze the data. First, 
the researcher is identified the data collected from Fifty Shades of Grey and Fifty Shades Darker movies, in the form ofdialogues, utterances and behaviors of Christian Grey and then the data obtained were analyzed. In this step, the researcher used the theory of Mangal (2008: 220-221) to analyze the causes of Christian Grey's sexual deviation and also used the theory of Ruben $(2015: 10)$ to analyze the personality impacts of his sexual deviation.

\section{FINDINGS AND DISCUSSION}

\section{Finding}

\section{Traumatic Experience}

Datum 001/FSOG/00:55:00-00:55:28

Ana: How did you start doing this?

Christian: From my mother's friend, I was fifteen.

Ana: She seduced you?

Christian: I was her submissive for six years.

Ana: Seriously? Does your mother know that?

Christian: Of course not. No one in my family knows about this part of me.

The dialogue is between Christian and Ana. Christian and Ana went for a walk in the wood when Christian drove Ana home. Ana asked Christian since when he had sexual deviation. Christian told Ana if he had it since he was fifteen years old. At that age, he was a submissive of his mother's (adoptive mother) friend for six years. Christian also told her if all of his family did not know about his past, Christian's family even did not know about his deviation. His past was kind of traumatic experience. Traumatic experience that happened to Christian when he was fifteen years old was typical sex violent (Mangal, 2008:220-221). Sex violent that happened to Christian was when he became a sexual submissive of his mother's friend and his traumatic experience in the early adulthood led him to have similar sexual deviation.

\section{Obsessive-Compulsive}

Datum 007/FSOG/00:05:11.

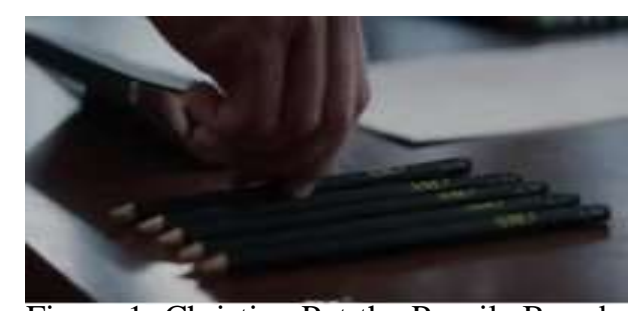

Figure 1. Christian Put the Pencils Based on the Length 
Figure 1 was Christian who put the pencils on the desk in orderline. He sorted he pencils from the shortest to the longest. Christian also took the pencil and given to Ana based in certain order. He took the shortest pencil from few pencils which lined up on his desk.. Figure 1 showed that Christian had the orderline characteristic which was one of the characteristics of obsessi vecompulsive personality (Ruben, 2015: 42). When he was a submissive of his adoptive mother's friend, he always struggled with orderline and rules, so he was accustomed to them and making orderline and rules became his personality.

\section{Histrionic}

Datum 005/FSOG/00:01:14-00:01:50

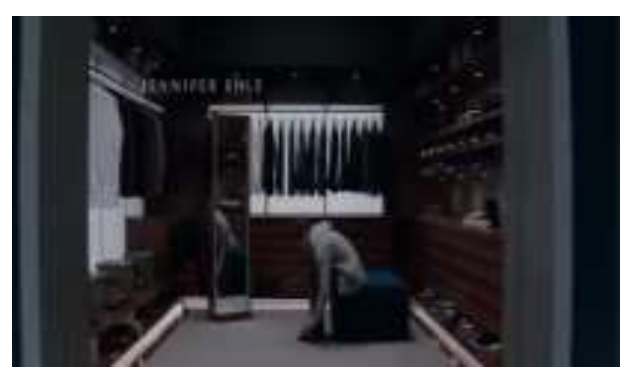

Figure 2 Christian Faced the Mirror

Figure 2 showed Christian who faced the mirror when he wore and tied his shoelaces. People with histrionic personality disorder were a self-centeredness and overly concerned with physical appearance (Ruben, 2015: 24). He was seeking the attention from himself, it meant Christian wanted to make sure he was still good looking, and he still got an attention from others.

\section{Discussion}

In Fifty Shades movie, the id of Christian appears in his desire, because the id was the birth present and it developed through the life experience of the person him/herself. Christian's desire was about the way how he did sexual activities. He did the sexual activities with a sadistic way. It began when he became a submissive of his adoptive mother's friend at fifteen years old until now, and his id worked because the desire about a sadistic way in his sexual activity with Ana who was willing to be an object of his id. The id worked without ego and superego because it was characterized by the id that wanted immediate satisfaction. In order to feel satisfied, Christian needed an ego and superego. In order 
to bridge the Christian's id, his ego worked to find a girl who wanted a sort of relationship like Christian wanted. Christian's id would never be satisfied if his ego did not work. Ego is also known as the executive of personality, because ego controls the way to fulfill the needs. In performing its functions, the ego works according to the reality principles, and in order to satisfy the id, ego has to find a goal of the object with suitable and acceptable ways.

The movies of Fifty Shades showed that the way Christian fulfilled his desire of sadistic sexual activity. He did anything to make Ana interacted with him. He seduced Ana with all ways, such as deliberately taking his cloth off, taking Ana with a helicopter, sent a huge bouquet of white roses, and how Christian explained in detail what he wanted in his relationship was his way to fulfill the needed. Christian's desire was a deviation any people did not agree with. Christian was hiding his desire of the sadistic things in sexual activity from others, even his family did not know about it. He also prepared a contract that explained if Ana should not tell anyone about what they had done.

The information shows how the superego worked. Super ego was known as a moral aspect personality, the function determines whether something is good or bad, right or wrong, fit or not, and many more with morality prevailed in society. That was the reason Christian hiding his sexual deviation from others. He did not want the society knew about it, because if society knew about his sexual deviation, all of things that he had built up like his image and his company would be ruined.

\section{CONCLUSION AND SUGGESTION}

\section{Conclusion}

After analyzing the data in previous chapters, the researcher has conclusion of this research. Christian is a person who has sexual deviation. He has the sexual deviation because his traumatic experience. Because of his sexual devition which was caused by his traumatic experience, Christian 
had personality disorders, such as histrionic, obsessive-compulsive, and narcissistic that become the impacts of sexual deviation. Fifty Shades movies are the movies that take the sexual deviation as the storylines. There are many sexual things of sadistic shown in this movies. In this movies, the deviation are presented by the actions of Christian. Fifty Shades also presented various devices that is used byChristian when he did sexual activities. This movies even presented how to use the devices. From the things that are shown by this movies, it means this movies support the sexual deviation, especially in sadistic ways.

\section{Suggestions}

This research is one way to interpret the literature. The movies can be analyzed from many points of view. The researcher suggests the next researchers who are interested in this movies to research more deeply. The researchers analyzed these movies by using other study approches, such as feminism, hegemony, and many more. The next researchers can also analyze other movies using psychological approach.

\section{REFERENCES}

Ahdiyatinuri, N. W. (2009). Sexual Deviaton Analysis on Sheba Hart's Character in Film Notes on A Scandal by Zoe Heller. S1 thesis, State Islamic University "Syarif Hidayatullah"

Jakarta.

Bilyarta, D. M. P. (2015). Christian Grey and Anastasia Steele'S Sexual Abnormality in E L James' Fifty Shades of Grey.S1 thesis, Sanata Dharma University Yogyakarta.

Bressler, E. C. (1994). Literary

Criticism: An Introduction to Theory and Practice, Second Edition. Prentice-Hall, Inc.

Freud, S. (1961). The resistances to psycho-analysis. In The Standard Edition of the Complete Psychological Works of Sigmund Freud, Volume XIX (1923-1925): The Ego and the Id and other works (pp. 211-224).

Guerin, L. W., Earle, L., Morgan, L., Jeanne, C. R., John, R. W. (2005). A Handbook of Critical Approaches to Literature. New york. Oxford University Press.

Mangal, S. K. (2008). Abnormal 
Putri Rochma Afifa and Dian Maya Kurnia, The Psychological Problems in Sexual Deviation of Christian Grey in Fifty Shades Movies

Psychology. $\quad$ Sterling

Publishers Pvt. Ltd.Oltmanns,

F. T., Emery. E. Robert. (2012).

Abnormal Psychology (7th

Edition). Pearson Publisher.

Pervin, L. A., Cervone, D., John, O.P. (2005). Personality: Theory and Research.Hoboken. NJ: Wiley.

Ruben, D. H. (2015). Behavioral Guide to Personality Disorders (DSM-5).Charles C Thomas Publisher.

Wening, P. G. (2016). Amy's Personality Disorder in Flynn's Gone Girl: A Psychological Approach. S1 thesis, Yogyakarta State University. 